Supporting Information for

\title{
In situ tracking of colloidally stable and orientationally ordered assemblies of gold nanorods
}

Dorota Grzelak $^{1}$, Piotr Szustakiewicz ${ }^{1}$, Christopher Tollan ${ }^{2}$, Sanoj Raj ${ }^{3}$, Petr Král ${ }^{3,4, *}$, Wiktor Lewandowski $^{1,5^{*}}$, Luis M. Liz-Marzán ${ }^{5,6^{*}}$

${ }^{1}$ Laboratory of organic nanomaterials and biomolecules, Faculty of Chemistry, University of Warsaw, Pasteura 1 st., Warsaw, 02-093, Poland

${ }^{2}$ Electron-Microscopy Laboratory, CIC nanoGUNE, Basque Research and Technology Alliance (BRTA), Tolosa Hiribidea 76, Donostia - San Sebastián, 20018, Spain

${ }^{3}$ Department of Chemistry, University of Illinois at Chicago, Chicago, Illinois, 60607, USA.

${ }^{4}$ Department of Physics, Biopharmaceutical Sciences, and Chemical Engineering, University of Illinois at Chicago, Chicago, Illinois, 60607, USA.

${ }^{5}$ CIC biomaGUNE, Basque Research and Technology Alliance (BRTA) and CIBER-BBN, Paseo de Miramón 182, Donostia - San Sebastián, 20014, Spain

${ }^{6}$ Ikerbasque, Basque Foundation for Science, 48013 Bilbao, Spain

Correspondence should be addressed to:

(email: 1lizmarzan@cicbiomagune.es, wlewandowski@chem.uw.edu.pl,pkral@uic.edu) 


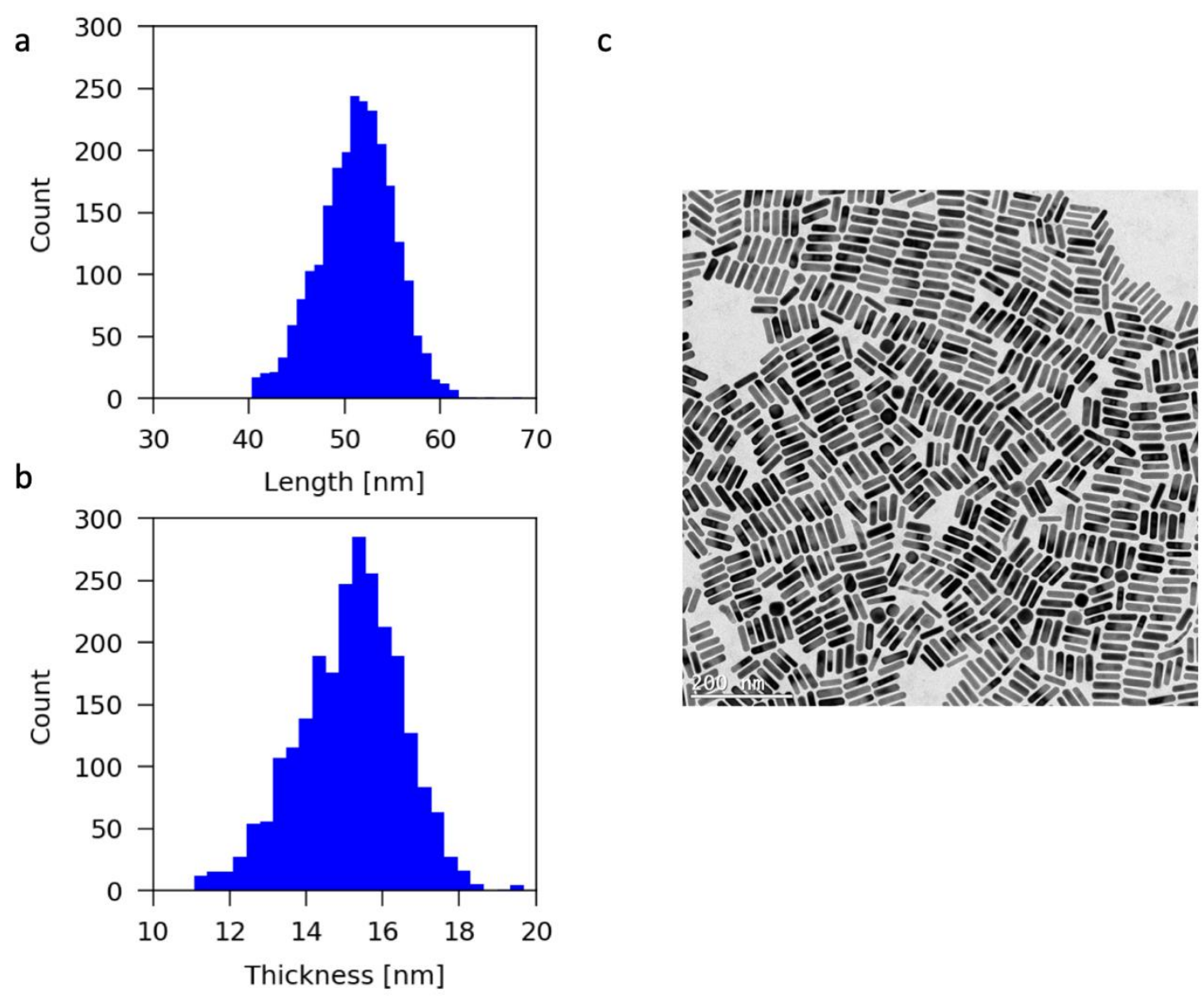

Fig. S1. Histograms of AuNRs length (a) and thickness (b) as calculated from TEM images. (c) Representative TEM image. Average length: $52 \pm 4 \mathrm{~nm}$, average thickness: $16 \pm 1 \mathrm{~nm}$.

\section{Supplementary Note 1: Reversibility of the assembly/disassembly process}

To test the reversibility of assembly/disassembly process we performed UV/Vis analysis of MUDOL-functionalized gold nanorods in the assembled/dispersed states. First, assembled NRs were prepared. Disassembly of NRs was achieved by heating and ultrasounds. The latter was used to increase the kinetics of the process, as explained in the manuscript. UV/Vis analysis of the redispersed material (Figure S2) revealed plasmonic band maxima characteristic to well dispersed AuNR@MUDOL. We also analyzed the influence the number of cycles on the disassembly performance. These measurements revealed that in consecutive measurements the longitudal plasmonic band exhibits redshift and decrease of intensity (4 $\mathrm{nm}$ and 20\%, respectively, after 3 cycles). These changes can be attributed e.g. to lowering of the disassembly efficiency (partial clustering of the sample) and/or irreversible absorption of NRs on the glass vial and/or partial degradation of the material. 


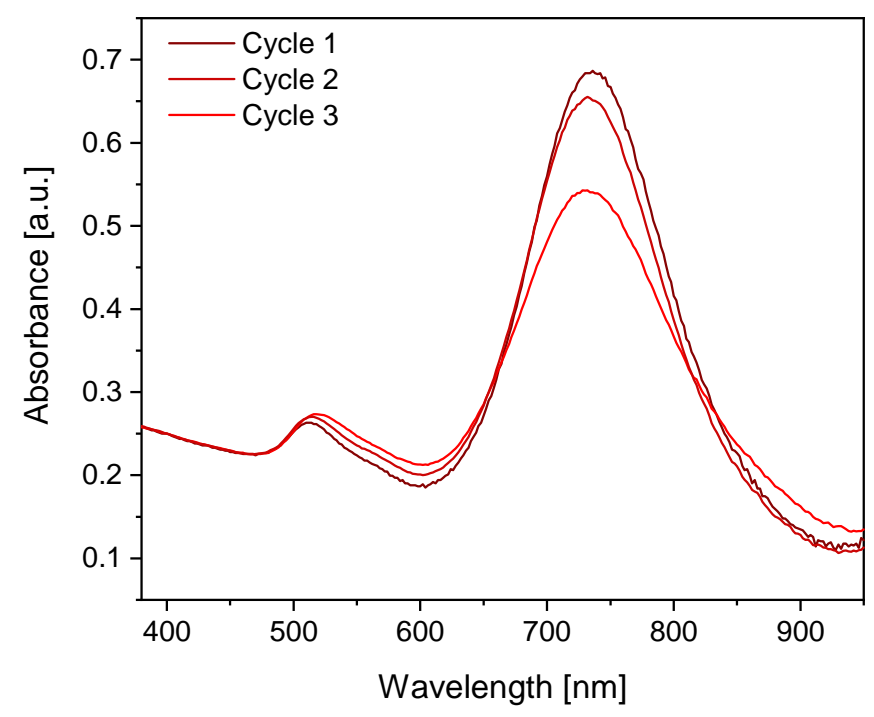

Fig. S2. UV/Vis spectra of the dispersed AuNR@MUDOL after consecutive assembly/disassembly cycles

\section{Supplementary Note 2: Electron beam induced thermal and charging effects}

To estimate the electron beam induced thermal effect during STEM measurements we turned to used an equation known from the literature ${ }^{\mathrm{S} 1, \mathrm{~S} 2}$ :

where

$$
\Delta T \cong \frac{I_{b}}{2 \pi^{2} e \kappa} \frac{d E}{d x} \ln \left(\frac{\pi}{2} \frac{a}{d}\right)
$$

$\Delta T$ - estimated temperature change

$\mathrm{I}_{\mathrm{b}}$ - beam current

$\mathrm{dE} / \mathrm{dx}$ - the energy loss rate per electron

$\kappa$ - thermal conductivity

a, $\mathrm{d}$ - estimated dimensions of the Field of View.

Based on the conditions we used in our experiments the effects should be below $1 \mathrm{~K}$.

To estimate the electron beam induced charging effect, we evaluated the charge flux during STEM measurements based on the experimentally measured beam current at $30 \mathrm{kV}(108 \mathrm{pA}$, measured using the Faraday cup), and beam conditions applied to all images and videos (Table $\mathrm{S} 1$ ). In detail, we calculated the number of electrons per second (based on the beam current), then recalculated the value per single frame (given the acquisition time of a single frame), and finally calculated the fluxes for different magnifications (variable size of the pixel). 
Table S1. Evaluation of the charge flux within the STEM chamber

\begin{tabular}{|c|c|c|c|c|}
\hline $\begin{array}{l}\text { Electrons per } \\
\text { Coulomb }\end{array}$ & \multicolumn{2}{|c|}{$6,24 * 10^{18}$} & \multicolumn{2}{|c|}{ electrons } \\
\hline Beam current & \multicolumn{2}{|c|}{$1,08 * 10^{-10}$} & \multicolumn{2}{|c|}{ Amper } \\
\hline $\begin{array}{l}\text { Electrons per second } \\
\text { (Full beam })\end{array}$ & \multicolumn{2}{|c|}{$6,74 * 10^{8}$} & \multicolumn{2}{|c|}{ electrons per second } \\
\hline Frame time & \multicolumn{2}{|c|}{0,116667} & \multicolumn{2}{|c|}{$\mathrm{sec}$} \\
\hline Electrons per frame & \multicolumn{2}{|c|}{$7,86^{*} 10^{7}$} & \multicolumn{2}{|c|}{ electrons } \\
\hline Total pixel number & \multicolumn{2}{|c|}{905216} & \multicolumn{2}{|c|}{ pixels $(1024 \times 884)$} \\
\hline Flux & \multicolumn{2}{|c|}{$7,45^{*} 10^{2}$} & \multicolumn{2}{|c|}{ electrons/pixels*seconds } \\
\hline \multicolumn{5}{|c|}{ Electron flux for representative magnifications } \\
\hline Magnification & $\begin{array}{l}\text { Pixel Height } \\
{[\mathrm{m}]}\end{array}$ & $\begin{array}{l}\text { Pixel Width } \\
{[\mathrm{m}]}\end{array}$ & $\begin{array}{c}\text { Surface } \\
{\left[\mathrm{A}^{2}\right]}\end{array}$ & $\begin{array}{l}\text { Calculated } \\
\quad \text { flux } \\
{\left[\mathrm{e} /\left(\mathrm{A}^{2 *} \mathrm{sec}\right)\right]}\end{array}$ \\
\hline $64000 x$ & $1,93 * 10^{-9}$ & $1,93 * 10^{-9}$ & 373,90 & 1,99 \\
\hline $91000 x$ & $1,37 * 10^{-9}$ & $1,37 * 10^{-9}$ & 186,95 & 3,98 \\
\hline $99000 x$ & $1,25 * 10^{-9}$ & $1,25 * 10^{-9}$ & 157,21 & 4,74 \\
\hline $128000 x$ & $9,67 * 10^{-10}$ & $9,67 * 10^{-10}$ & 93,48 & 7,97 \\
\hline $140000 x$ & $8,87 * 10^{-10}$ & $8,87 * 10^{-10}$ & 78,60 & 9,47 \\
\hline $186000 x$ & $6,66 * 10^{-10}$ & $6,66 * 10^{-10}$ & 44,34 & 16,79 \\
\hline
\end{tabular}

a
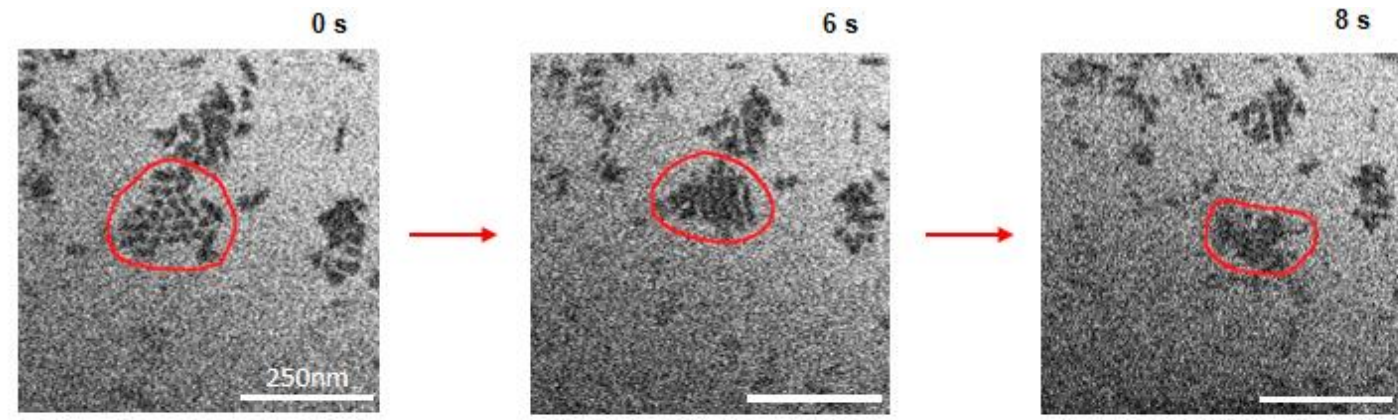

b

$0 \mathrm{~s}$
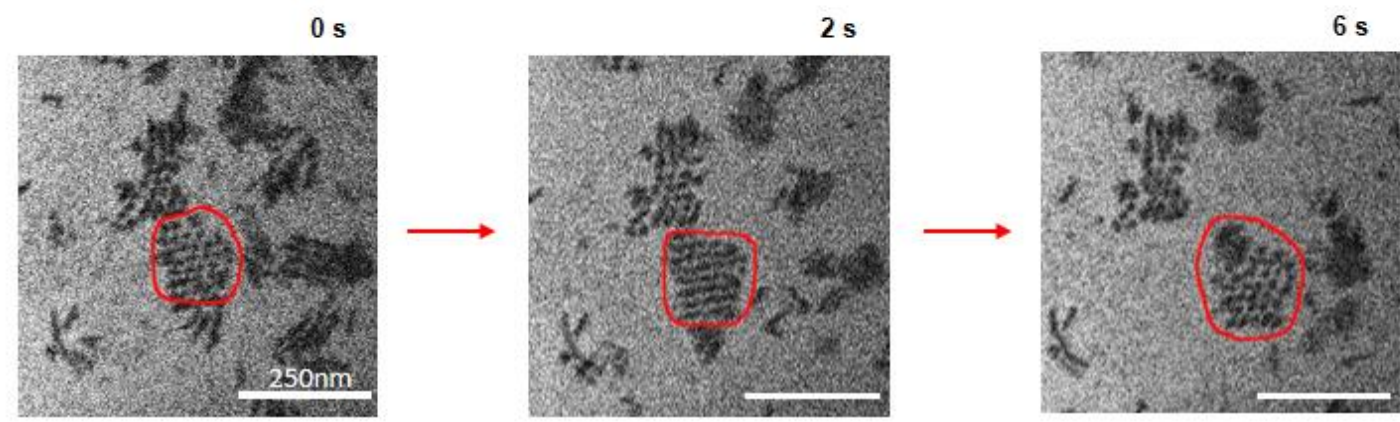

Fig. S3.AuNR@MUDOL vertical aggregate images recorded via WetSTEM showing examples of movements of oriented AuNR clusters; (a) Example 1, snapshots from MovieS3; (b) Example 2, snapshots from MovieS4. 


\section{Modeling notes and figures}

\section{Mean-field modeling of bulk vdW and Coulombic coupling between large NRs}

Figure S4 (A) show the calculated bulk vdW and Coulombic coupling energies, respectively, between pairs of small and large NRs in bulk water. Figure S4 (B) shows the total coupling energies calculated for large NRs with differently charged surfaces with water as a solvent.
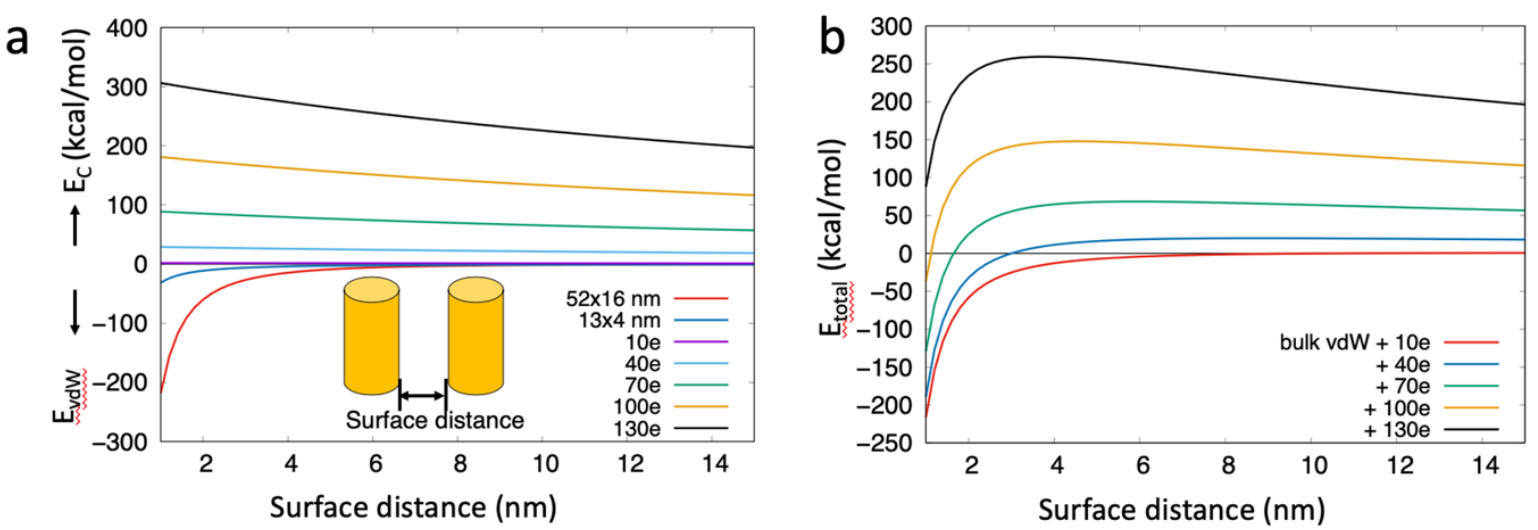

Fig. S4. Mean-field modeling of AuNRs (a) vdW coupling energies ( $E_{v d W}$ ) between two AuNRs (52 x $16 \mathrm{~nm}$ and $13 \times 4 \mathrm{~nm}$ ) and Coulombic coupling energies ( $\left.E_{C}\right)$ between two AuNRs $(52 \times 16 \mathrm{~nm})$. (b) Total interaction energies $\left(\mathrm{E}_{\mathrm{total}}=\mathrm{E}_{\mathrm{vdW}}+\mathrm{E}_{\mathrm{C}}\right)$ between AuNRs $(52 \times 16 \mathrm{~nm})$.

\section{Supplementary Note 3. MD-simulated stabilization of neutral small, partially submerged AuNR@MUDOL}

To understand the self-assembly of AuNRs, seven neutral small AuNR@MUDOL were simulated in a $400 \times 400 \times 200 \AA^{3}$ water box. AuNRs were placed at a center-to-center distance of $\sim 8 \mathrm{~nm}$ from each other in a hexagonal pattern and were partially submerged. MD simulation was performed in an NVT ensemble at $\mathrm{T}=300 \mathrm{~K}$. The system was equilibrated for $15 \mathrm{~ns}$ when the distance between the AuNRs stopped changing (for $2 \mathrm{~ns}$ ) and the AuNRs were mostly submerged in water, as shown in Fig. S5a. More precisely, AuNRs tips, from one side, were exposed to vacuum (above water surface), while from the other side tips were fully submerged. This system provided a starting point for the MD simulations of thermally and charge driven disassembly, which was done by transferring the equilibrated AuNRs cluster to water or glycerol, with an additional top layer of solvent. 
a

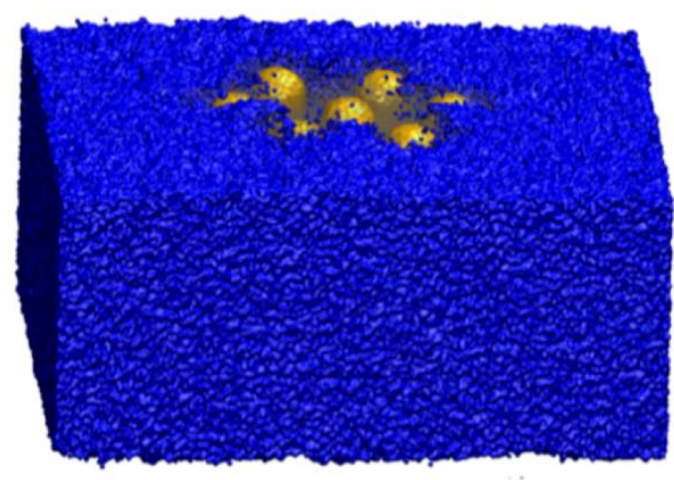

b

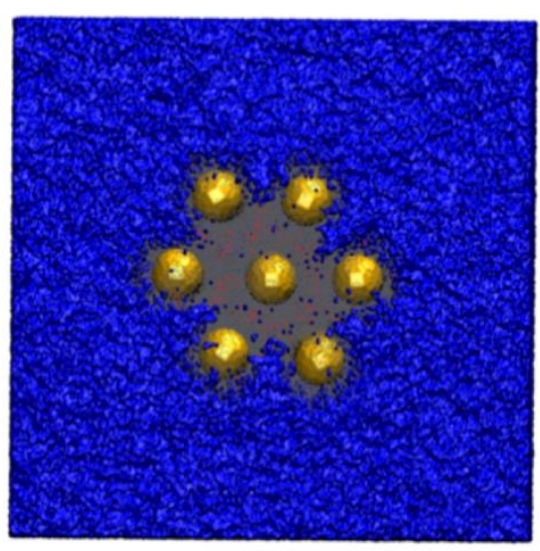

Fig. S5. Starting point for stimuli-responsive disassembly modelling (a) Edge view and (b) top view of the small, partially exposed NRs in water at $25{ }^{\circ} \mathrm{C}$ equilibrated system at $15 \mathrm{~ns}$ simulation. NRs, ligands, and water are shown in yellow, grey, and blue, respectively.

Table S2. Summary of MD simulations of disassembly

\begin{tabular}{|c|c|c|c|c|c|c|c|}
\hline $\begin{array}{c}\text { Simulation } \\
\text { number }\end{array}$ & $\begin{array}{c}\text { Charge } \\
\text { (electrons } \\
\text { per NP) }\end{array}$ & $\begin{array}{c}\text { Temper } \\
\text { ature } \\
\left({ }^{\circ} \mathrm{C}\right)\end{array}$ & $\begin{array}{c}\text { Solvent (type, } \\
\text { submerged vs. } \\
\text { partially exposed } \\
\text { NRs) }\end{array}$ & Data & $\begin{array}{c}\text { Simulation } \\
\text { time (ns) }\end{array}$ & $\begin{array}{c}\text { Initial } \\
\text { averaged } \\
\text { distance } \\
(\mathbf{n m})\end{array}$ & $\begin{array}{c}\text { Final } \\
\text { averaged } \\
\text { distance } \\
\text { (nm) }\end{array}$ \\
\hline 1 & 0 & 25 & $\begin{array}{c}\text { glycerol, fully } \\
\text { submerged }\end{array}$ & $\begin{array}{c}\text { Figure } \\
\text { S6 }\end{array}$ & 15 & $\sim 3.0$ & $\sim 3.0$ \\
\hline 2 & 0 & 150 & $\begin{array}{c}\text { glycerol, fully } \\
\text { submerged }\end{array}$ & $\begin{array}{c}\text { Figure } \\
\text { 5c-e }\end{array}$ & 28 & $\sim 3.0$ & $\sim 4.3$ \\
\hline 3 & 0 & 100 & $\begin{array}{c}\text { water, partially } \\
\text { submerged }\end{array}$ & $\begin{array}{c}\text { Figure } \\
\text { S8a,b }\end{array}$ & 35 & $\sim 3.0$ & $\sim 4.3$ \\
\hline 4 & 0 & 100 & $\begin{array}{c}\text { water, fully } \\
\text { submerged }\end{array}$ & $\begin{array}{c}\text { Figure } \\
\text { S8c,d }\end{array}$ & 15 & $\sim 4.3$ & $\sim 4.5$ \\
\hline 5 & 20 & 25 & $\begin{array}{c}\text { water, partially } \\
\text { submerged }\end{array}$ & $\begin{array}{c}\text { Figure } \\
\text { S7a,b }\end{array}$ & 30 & $\sim 3.0$ & $\sim 3.2$ \\
\hline 6 & 20 & 25 & $\begin{array}{c}\text { water, fully } \\
\text { submerged }\end{array}$ & $\begin{array}{c}\text { Figure } \\
\text { S7c,d }\end{array}$ & 15 & $\sim 3.2$ & $\sim 3.2$ \\
\hline 7 & 50 & 25 & $\begin{array}{c}\text { water, partially } \\
\text { submerged }\end{array}$ & $\begin{array}{c}\text { Figure } \\
\text { S7e-f }\end{array}$ & 30 & $\sim 3.0$ & $\sim 6.1$ \\
\hline 8 & 50 & 25 & $\begin{array}{c}\text { water, fully } \\
\text { submerged }\end{array}$ & $\begin{array}{c}\text { Figure } \\
5 \mathrm{f}-\mathrm{h}\end{array}$ & 30 & $\sim 3.0$ & $\sim 6.1$ \\
\hline
\end{tabular}

\section{Supplementary Note 4. MD-simulated thermally-driven disassembly of neutral small}

\section{AuNR@MUDOL submerged in glycerol}

We modeled the disassembly of seven AuNR@MUDOL submerged in glycerol. We took the self-assembled system in Fig. S5 and submerged them in 320 x 320 x $280 \AA^{3}$ glycerol box. We did not observe the disassembly process in a given simulation time $(\sim 15 \mathrm{~ns})$ in contrast to analogous simulation performed at $150{ }^{\circ} \mathrm{C}$ (Fig. 5c,d in the main text). 
a

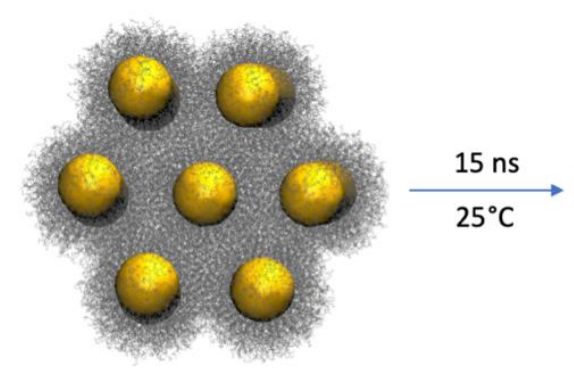

b

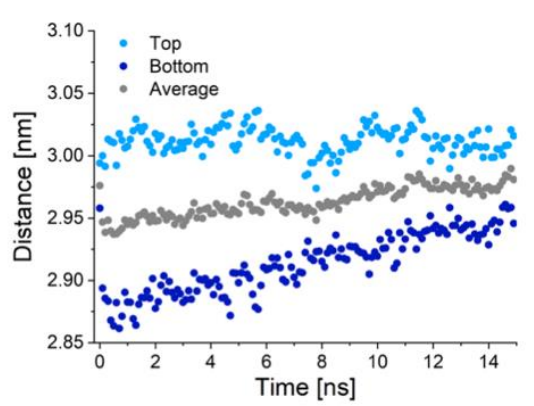

Fig. S6 (a) MD simulation of AuNR@MUDOL cluster of neutral AuNRs fully submerged in glycerol at $25^{\circ} \mathrm{C}$. Water molecules are removed for clarity. (b) Time evolution of the average distances between the top, bottom, and average distances of AuNRs shown in (a).

\section{Supplementary Note 5. MD-simulated charge-driven disassembly of small AuNR@MUDOL}

Here, we modeled the disassembly of seven charged (20 e and 50 e each) AuNR@MUDOL partially and fully submerged in water at $25{ }^{\circ} \mathrm{C}$. We started with the self-assembled system as shown in Fig. S5 and charged the AuNRs with 20 e. Within 30 ns simulation time, we did not observe the disassembly of the AuNRs (Fig. S7a-b). For a fully submerged system, we took the final configuration from a previous simulation (Fig. S7a) and added a $5 \mathrm{~nm}$ layer of water, to cover the exposed AuNR@MUDOL part. Then, we continued the simulation for another $15 \mathrm{ns,}$ which still did not show any disassembly of the AuNRs (Fig. S7c-d). This methodology allowed us to shorten the total simulation time required. When the self-assembled system in Fig. S5 was taken and charged with 50 e, the AuNRs disassembled within $30 \mathrm{~ns}$, regardless of whether the AuNR@MUDOL were partially exposed (Fig. S7e-f) or fully submerged in water (Fig. 5f,g). The highly charged AuNRs, which were partially submerged (tips from one side exposed above the water surface) separated in a tilted manner (Fig. S7e-f), with the top parts always closer to each other than the lower parts, since their ligands couple stronger in a vacuum, in contrast to the fully submerged system AuNRs which exhibit a trembling behavior observed for experimental cases (Fig. 5g,h). 

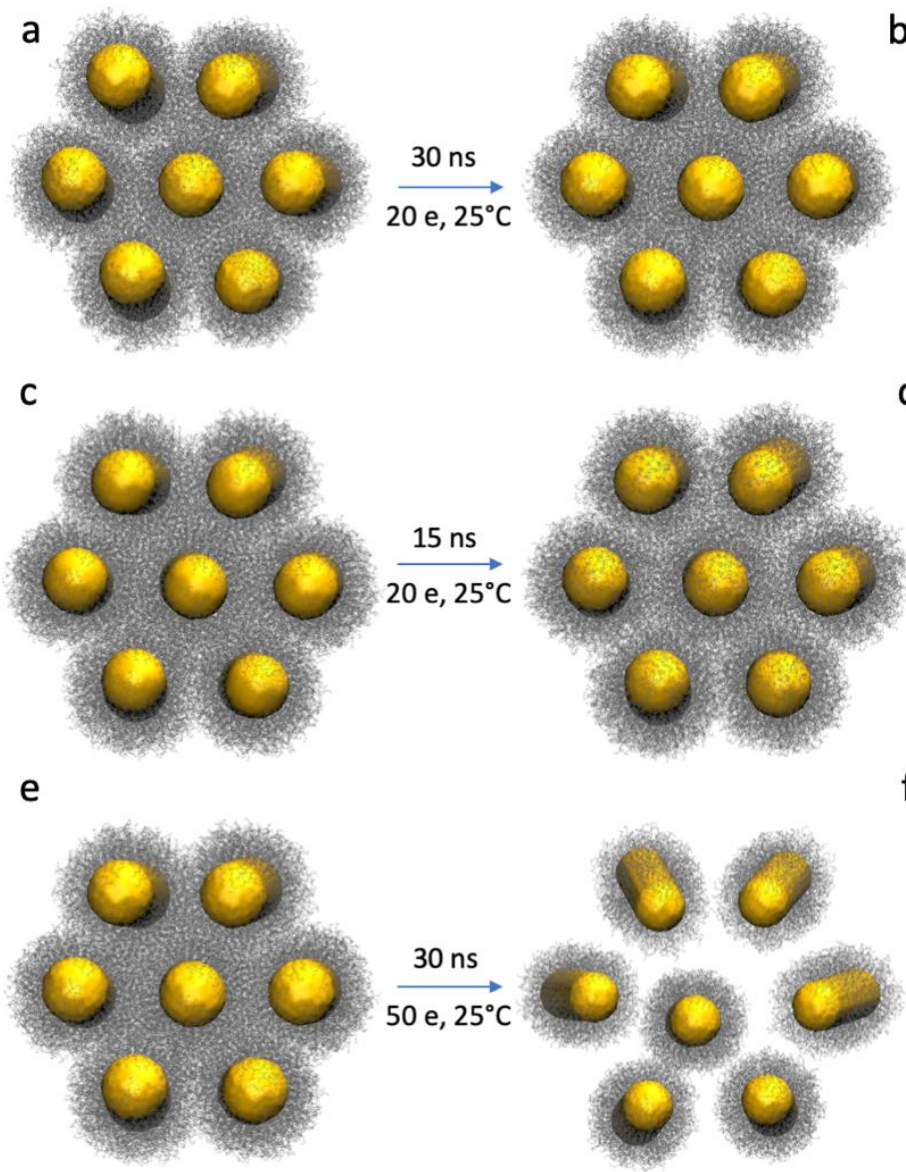

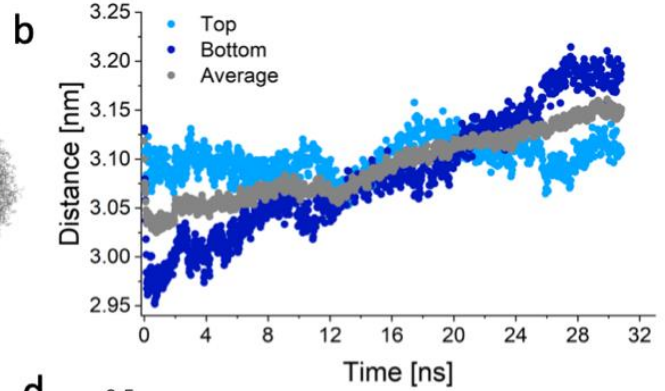

d

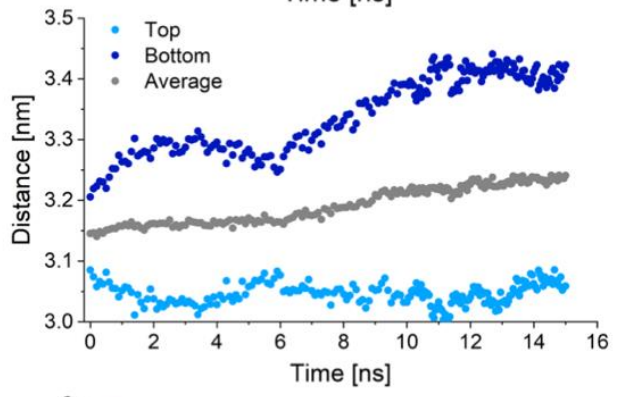

f

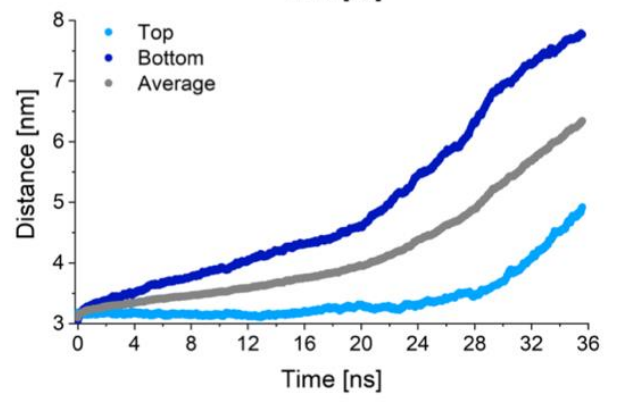

Fig. S7. (a) MD simulation of AuNR@MUDOL cluster under a charge of 20 e per AuNR; AuNRs partially submerged in water. Water molecules are removed for clarity. b) Time evolution of the average distances between the top, bottom, and average distances of AuNRs shown in (a). (c) MD simulation of AuNR@MUDOL disassembly process under a charge of 20 e per AuNR; AuNRs submerged in water by adding a layer of water to the final configuration obtained in (a). d) Time evolution of the average distances between the top, bottom, and average distances of AuNRs shown in (c); due to the modelling methodology described above, this graph is a continuation of the graph shown in (b). (e) MD simulation of AuNR@MUDOL disassembly process under a charge of 50 e per AuNR; AuNRs partially submerged in water. f) Time evolution of the average distances between the top, bottom, and average distances of neutral AuNRs shown in (e).

\section{Supplementary Note 6. MD-simulated temperature driven disassembly of small AuNR@MUDOL}

Here, we modeled the disassembly of seven neutral AuNR@MUDOL partially and fully submerged in water at $100{ }^{\circ} \mathrm{C}$. When the neutral system as shown in Fig. S5 was equilibrated for $35 \mathrm{~ns}$ at $100{ }^{\circ} \mathrm{C}$ (Fig. S8a), the center-to-center distance between AuNRs changed from 3.0 
to $4.3 \mathrm{~nm}$, as shown in Fig. S8b. Even though the system seems to gradually disassemble, the AuNRs stay close to each other, keeping the orientational and hexagonal order for a longer period than in the case of higher temperatures (simulation performed at $150{ }^{\circ} \mathrm{C}$ in a bulk glycerol, Fig. 5d,e). To model the disassembly of seven AuNR@MUDOL submerged in water, we took the final configuration of the system shown in Fig. S8a and added a $5 \mathrm{~nm}$ layer of water to cover the exposed AuNR@MUDOL surface, so that AuNRs were fully submerged. We ran the simulation in NPT ensemble for the $15 \mathrm{~ns}$ and we observed that the center-to-center distance between AuNRs changed from 4.3 to 4.5 nm, as shown in Fig. S8c-d. This methodology allowed us to shorten the total simulation time required. With these simulations we confirm that thermal effects can help in the disassembly process.
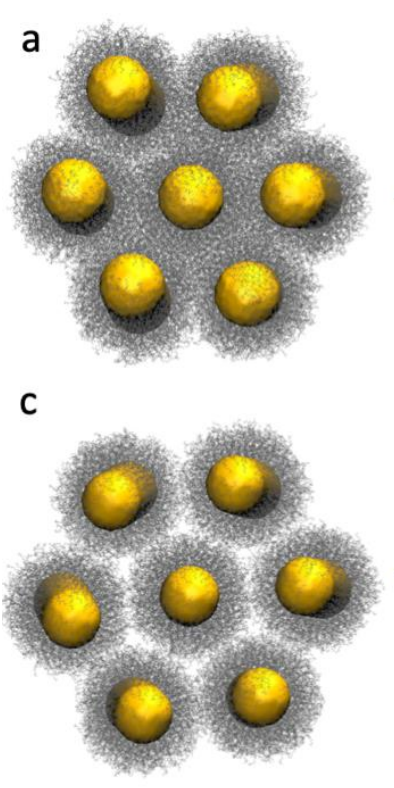
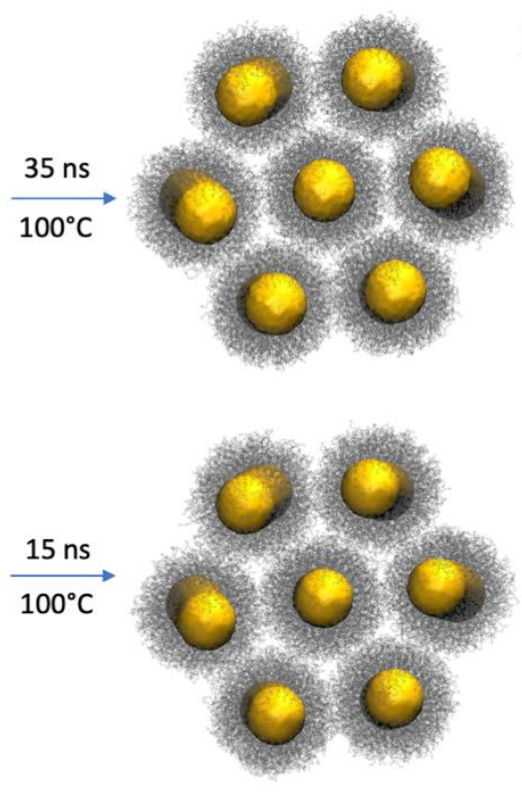

\section{b}

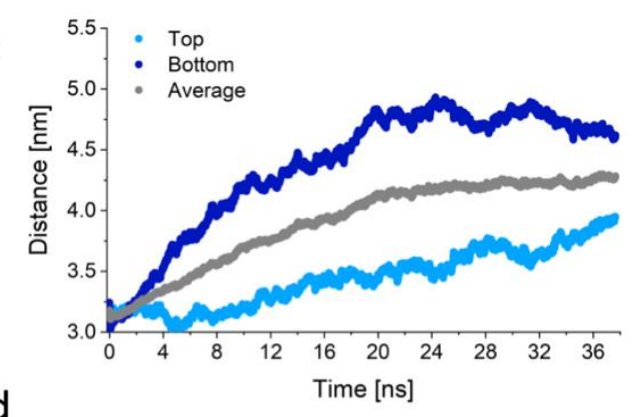

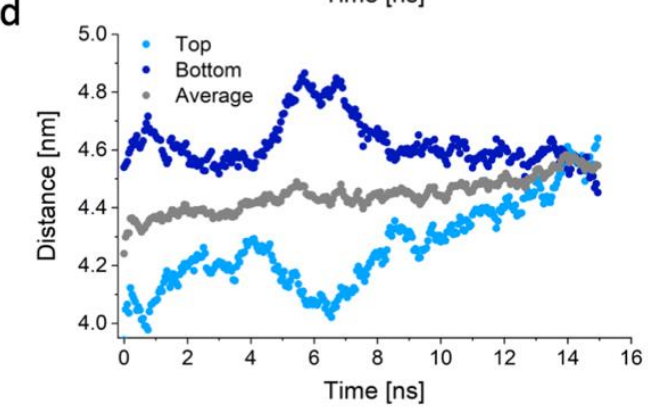

Fig. S8. (a) MD simulation of neutral AuNR@MUDOL partially submerged in water, disassembling at $100{ }^{\circ} \mathrm{C}$. Water molecules are removed for clarity. (b) Time evolution of the distances between the top, bottom, and average distances of neutral AuNRs shown in (a). (c) MD simulation of AuNR@MUDOL disassembly process $100^{\circ} \mathrm{C}$; AuNRs submerged in water by adding a layer of water to the final configuration obtained in (a). Water molecules are removed for clarity. (d) Time evolution of the average distances between the top, bottom, and average distances of AuNRs shown in (c); due to the modelling methodology described above, this graph is a continuation of the graph shown in (b). 
Table S3. Summary of Supplementary Movies

\begin{tabular}{|c|c|c|}
\hline Symbol & Figure & Content \\
\hline Movie S1 & Figure $3 b$ & $\begin{array}{c}\text { WetSTEM recording of an AuNR@MUDOL vertical } \\
\text { aggregate, showing a single nanoparticle detaching from the } \\
\text { aggregate. }\end{array}$ \\
\hline Movie S2 & Figure $3 d$ & $\begin{array}{l}\text { WetSTEM recording of an AuNR@ MUDOL vertical } \\
\text { aggregate, showing an example of AuNR cluster } \\
\text { displacement. }\end{array}$ \\
\hline Movie S3 & Figure S2a & $\begin{array}{l}\text { WetSTEM recording showing an example of oriented } \\
\text { clusters of AuNRs movements. }\end{array}$ \\
\hline Movie S4 & Figure $S 2 b$ & $\begin{array}{l}\text { WetSTEM recording showing an example of oriented } \\
\text { clusters of AuNRs movements. }\end{array}$ \\
\hline Movie S5 & $\begin{array}{c}\text { Additional } \\
\text { material }\end{array}$ & $\begin{array}{l}\text { WetSTEM recording showing multiple events of AuNRs } \\
\text { trembling rapidly and losing orientational correlation. }\end{array}$ \\
\hline Movie S6 & Figure $4 b$ & $\begin{array}{l}\text { WetSTEM recording of the disassembly of an } \\
\text { AuNR@MUDOL aggregate. }\end{array}$ \\
\hline Movie S7 & Figure $4 d$ & $\begin{array}{l}\text { WetSTEM recording of the disassembly of an } \\
\text { AuNR@MUDOL aggregate. }\end{array}$ \\
\hline Movie S8 & Figure $4 \mathrm{f}$ & $\begin{array}{l}\text { WetSTEM recording of the disassembly of an } \\
\text { AuNR@MUDOL aggregate. }\end{array}$ \\
\hline Movie S9 & Figure $5 d$ & $\begin{array}{l}\text { MD simulation of small neutral AuNRs disassembling in } \\
\text { glycerol at } 150^{\circ} \mathrm{C}\end{array}$ \\
\hline Movie S10 & Figure $5 \mathrm{~g}$ & $\begin{array}{l}\text { MD simulation of small neutral AuNRs disassembling under } \\
\qquad 50 \text { e charge in the water at } 25^{\circ} \mathrm{C}\end{array}$ \\
\hline Movie S11 & $\begin{array}{c}\text { Additional } \\
\text { material }\end{array}$ & $\begin{array}{c}\text { Recording of AuNR@ MUDOL clusters disassembling with } \\
\text { reversed time }\end{array}$ \\
\hline Movie S12 & $\begin{array}{l}\text { Additional } \\
\text { material }\end{array}$ & $\begin{array}{c}\text { Recording of AuNR@MUDOL clusters disassembling with } \\
\text { reversed time }\end{array}$ \\
\hline
\end{tabular}

\section{References:}

1. Kohl, H.; Rose, H.; Schnabl, H. Dose-rate effect at low temperatures in FBEM and STEM due to object-heating. Optik (Stuttg). 58, 11-24 (1981). 
2. White, E. R., Mecklenburg, M., Shevitski, B., Singer, S. B. \& Regan, B. C. Charged nanoparticle dynamics in water induced by scanning transmission electron microscopy. Langmuir 28, 3695-3698 (2012). 